\title{
Performance Degradation of Dye-Sensitized Solar Cells Induced by Electrolytes
}

\author{
Ru-Yuan Yang, ${ }^{1}$ Huang-Yu Chen, ${ }^{2}$ and Fu-Der Lai ${ }^{2}$ \\ ${ }^{1}$ Graduate Institute of Materials Engineering, National Ping-Tung University of Science and Technology, Pingtung 912, Taiwan \\ ${ }^{2}$ Institute of Electro-Optical Engineering, National Kaohsiung First University of Science and Technology, Kaohsiung 811, Taiwan
}

Correspondence should be addressed to Ru-Yuan Yang, ryyang@mail.npust.edu.tw

Received 14 June 2012; Revised 7 August 2012; Accepted 7 August 2012

Academic Editor: Yu-Pei Huang

Copyright ( $) 2012 \mathrm{Ru}$-Yuan Yang et al. This is an open access article distributed under the Creative Commons Attribution License, which permits unrestricted use, distribution, and reproduction in any medium, provided the original work is properly cited.

\begin{abstract}
We investigated the change of the electric characteristics in dye-sensitized solar cell (DSSC) when the electrolyte has been injected and measured initially and lately for a period of time. It was found that the short-circuit current density decreased from $9.799 \mathrm{~mA} / \mathrm{cm}^{2}$ to $7.056 \mathrm{~mA} / \mathrm{cm}^{2}$ and the fill factor increased from 0.406 to 0.559 when the cell had stood for an hour, while the open-circuit photovoltage did not change due to fixed difference between the Fermi level of $\mathrm{TiO}_{2}$ and the oxidation-reduction potential of electrolyte. The results can be explained by using the variation of the series resistance in the equivalent circuit of the DSSC.
\end{abstract}

\section{Introduction}

Dye-sensitized solar cells (DSSC) have attracted much attention ever since Grätzel et al. demonstrated the possibility to convert solar energy to electricity with a photoelectrochemical dye-sensitized device [1]. The DSSC provides a technically and economically credible alternative concept to present day $\mathrm{p}-\mathrm{n}$ junction photovoltaic devices. The development of these new types of solar cell is promoted by the increasing public awareness that the earth's oil reserves will run out during this century. Because the energy needs of the planet will at least double within the next 50 years, the stage is set for a major shortage of energy supply unless renewable sources can cover the substantial deficit that fossil fuels can no longer furnish.

This accomplishes the optical absorption and charge separation processes by the association of a sensitizer as a light-absorbing material with a wide-band-gap semiconductor of mesoporous or nanocrystalline morphology [1-3]. It also offers the prospect of very low cost fabrication without expensive and energy-intensive high-temperature and highvacuum processes, compatibility with flexible substrates, and variety of presentations and appearances to facilitate market entry, both for domestic devices and in architectural or decorative applications. Generally, the semiconductor, which accepts the electron from the sensitizer and transfers it to the electrode, is nanocrystalline anatase $\mathrm{TiO}_{2}$ which is mesoporous because of high surface area. High surface area of $\mathrm{TiO}_{2}$ thin film improves the adsorption of sensitizer and hence increases the light-harvesting capacity of the mesoporous film. However, the electrolyte may penetrate into the mesoporous film and contact the dye-free $\mathrm{TiO}_{2}$ and the electrode surface, resulting in the increase of the reverse saturation current. On the other hand, it also increases the contact area between the electrolyte and the sensitizer so that facilitates the reduction of $I_{3}{ }^{-}$by the combination of the hole. It was found that the short-circuit photocurrent decreased and the fill factor of the dye-sensitized solar cell increased as time goes on.

In this study, the change of the electric characteristics in dye-sensitized solar cell (DSSC) when the electrolyte has been injected and measured initially and lately for a period of time was investigated. The short-circuit photocurrent density $\left(J_{\text {sc }}\right)$ and the fill factor (F.F.) were varied and the results can be explained by using the variation of the series resistance in the equivalent circuit of the DSSC.

\section{Experimental Apparatus and Procedure}

2.1. Preparing the Working Electrode. $\mathrm{A} \mathrm{TiO}_{2}$ thin-film electrode was designed and fabricated for use in a dye-sensitized solar cell. This $\mathrm{TiO}_{2}$ thin-film was deposited on the top of 


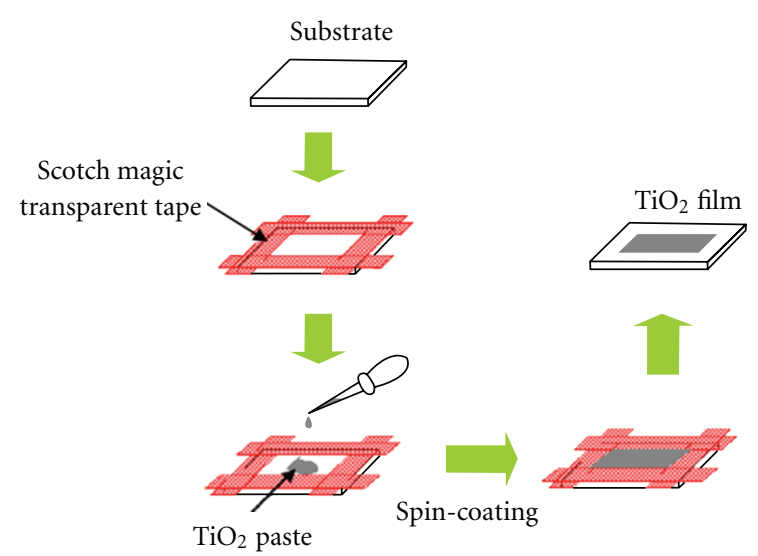

FIGURE 1: The procedure of preparing the working electrode.

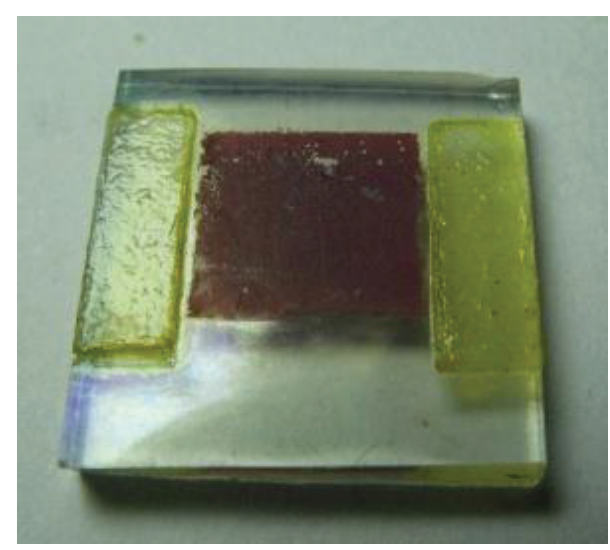

FIGURE 2: The photograph of the working electrode. an FTO-glass (Fluorine doped tin oxide, $\mathrm{SnO}_{2}: \mathrm{F}$ ) substrate, which has a size of $20 \times 20 \times 3 \mathrm{~mm}$ and a sheet resistance of $8 \Omega /$ sq. The $\mathrm{TiO}_{2}$ particles (P-25) are composed of $30 \%$ rutile and $70 \%$ anatase, with a particle size range $(<100 \mathrm{~nm})$.

Figure 1 shows the procedure of preparing the working electrode of DSSC with a layer of $\mathrm{TiO}_{2}$ particles and the steps are described as follows. (1) Diluting $40 \mu \mathrm{L}$ of acetylacetone in $1 \mathrm{~mL}$ of de-ionic (DI) water; (2) mixing $1 \mathrm{~g}$ of $\mathrm{TiO}_{2}$ particles with the diluted acetylacetone, and stir well to make the colloid of $\mathrm{TiO}_{2}$ particles; (3) adjusting the glutinosity of the colloid of $\mathrm{TiO}_{2}$ particles by adding $1.5 \mathrm{~mL}$ of DI water and $40 \mu \mathrm{L}$ of surfactant (Triton-100, $\left.\mathrm{C}_{8} \mathrm{H}_{17} \mathrm{C}_{6} \mathrm{H}_{4}\left(\mathrm{OCH}_{2} \mathrm{CH}_{2}\right) \mathrm{nOH}\right)$, and then homogenize the colloid of $\mathrm{TiO}_{2}$ particles for 30 minute in a mortar; (4) dropping the quantitative colloid of $\mathrm{TiO}_{2}$ particles on the top of the $\mathrm{F}: \mathrm{SnO}_{2}$ (FTO) glass substrate, and then spin coat the working electrode with rotational speed of $3000 \mathrm{rpm}$; (5) drying the working electrode with a layer of $\mathrm{TiO}_{2}$ particles at room temperature for 10 minute, and then sinter this working electrode at $500^{\circ} \mathrm{C}$ for 30 minutes in a hightemperature furnace; (6) immersing the FTO-glass substrate with a layer of $\mathrm{TiO}_{2}$ particles into the $\left(3 \times 10^{-4} \mathrm{~mol} / \mathrm{L}\right)$ solution of $\mathrm{N}-719$ dye (Ruthenium, $\mathrm{RuL}_{2}(\mathrm{NCS})_{2}$ ) and ethyl alcohol $\left(\mathrm{CH}_{3} \mathrm{CH}_{2} \mathrm{OH}, 95 \%\right)$ for 24 hours at room temperature. A conventional working electrode with a layer of nanocrystalline $\mathrm{TiO}_{2}$ on the FTO-glass substrate was fabricated using above procedures to demonstrate the feasibility and advantages of the working electrode with a layer of $\mathrm{TiO}_{2}$ particles. An $\alpha$-step (Dekeak $6 \mathrm{M}$ ) surface profiler was utilized to obtain the surface profile of the thin film and the average thickness of the thin film on the FTO-glass substrate of the working electrode. The thickness of the $\mathrm{TiO}_{2}$ thin films was about $10 \mu \mathrm{m}$. Figure 2 shows the practical working electrode.

2.2. Assembling the DSSC. Figure 3 shows the schematic of the DSSC. The thin film on the FTO-glass substrate of the working electrode was fringed using the Scotch magic transparent tape $(3 \mathrm{M})$. Then, the working electrode and the counter electrode that a thin film of platinum was deposited on the FTO-glass substrate using a ion sputter (Hitachi E1010) were fitted together, such that the space between the two electrodes was adjusted to approximately $160 \mu \mathrm{m}$ for embarking the liquid electrolyte. After sealing, the liquid electrolyte, which was composed of $0.5 \mathrm{M}$ lithium iodine (LiI) and 0.05 M iodine $\left(\mathrm{I}_{2}\right)$ in 3-methoxypropionitrile, was injected into the cell through a hole on the cell that was prepared in advance.

2.3. Testing. A home-made $I-V$ measurement system was adopted to measure the open-circuit photovoltage and shortcircuit photocurrent of the DSSC. A solar simulator with a $500 \mathrm{~W}$ halogen lamp and a light intensity of $100 \mathrm{~mW} / \mathrm{cm}^{2}$, was employed to illuminate the DSSC. In addition, the power conversion efficiency $\eta$ of the DSSC was determined by

$$
\eta(\%)=\frac{V_{\mathrm{oc}} J_{\mathrm{sc}} \mathrm{FF}}{P_{\mathrm{in}}} \times 100 .
$$

In (1), $V_{\mathrm{oc}}, J_{\mathrm{sc}}$, and $P_{\text {in }}$ represent the open-circuit voltage, the short-circuit current density, and the incident light power $\left(100 \mathrm{mw} / \mathrm{cm}^{2}\right)$, respectively. Moreover, the fill factor FF is given by

$$
\mathrm{FF}=\frac{V_{\mathrm{max}} J_{\mathrm{max}}}{V_{\mathrm{oc}} J_{\mathrm{sc}}} .
$$

In (2), $V_{\max }$ and $I_{\max }$ represent the voltage and the current at the maximum output power point, respectively. The $I-V$ characteristics of the prepared DSSC were measured at initial assembling stage and at one hour lately.

\section{Results and Discussion}

Figure 4 shows $I-V$ characteristics of the DSSC when the electrolyte is just injected into the space between the working electrode and the counter electrode. The measured $V_{\mathrm{oc}}, J_{\mathrm{sc}}$, and F.F. are $9.799 \mathrm{~mA} / \mathrm{cm}^{2}, 0.658 \mathrm{~V}$, and 0.406 , respectively. Figure 5 shows $I-V$ characteristics of the dye-sensitized solar cell after the electrolyte has been injected and stay for one hour. The measured $V_{\mathrm{oc}}, J_{\mathrm{sc}}$, and F.F. are $7.056 \mathrm{~mA} / \mathrm{cm}^{2}$, $0.668 \mathrm{~V}$, and 0.559 , respectively. as Comparing Figure 4 to Figure 5, it is found that the $J_{\text {sc }}$ decreases from $9.799 \mathrm{~mA} / \mathrm{cm}^{2}$ to $7.056 \mathrm{~mA} / \mathrm{cm}^{2}$ and F.F increases from 0.406 to 0.559 . The $V_{\text {oc }}$ does not change due to the fixed difference between 


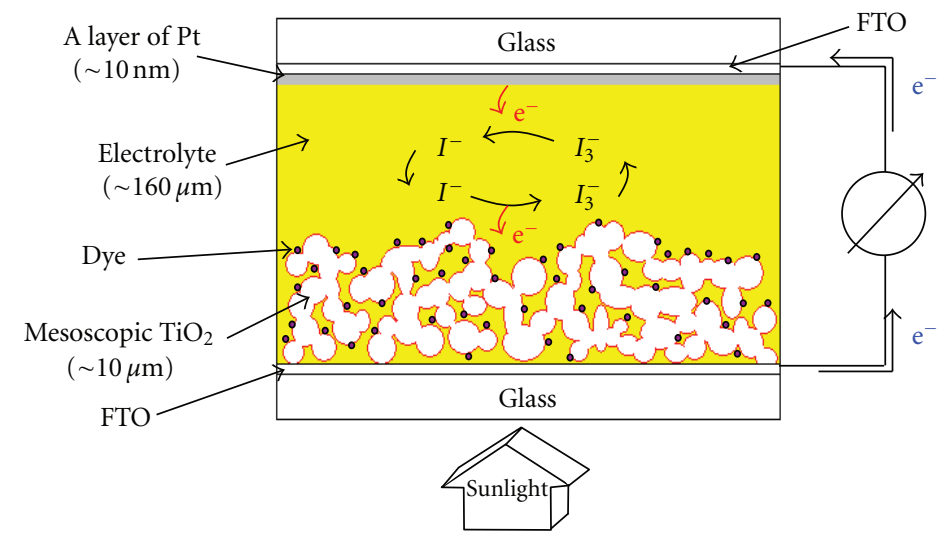

Figure 3: Schematic of the dye-sensitized solar cell.

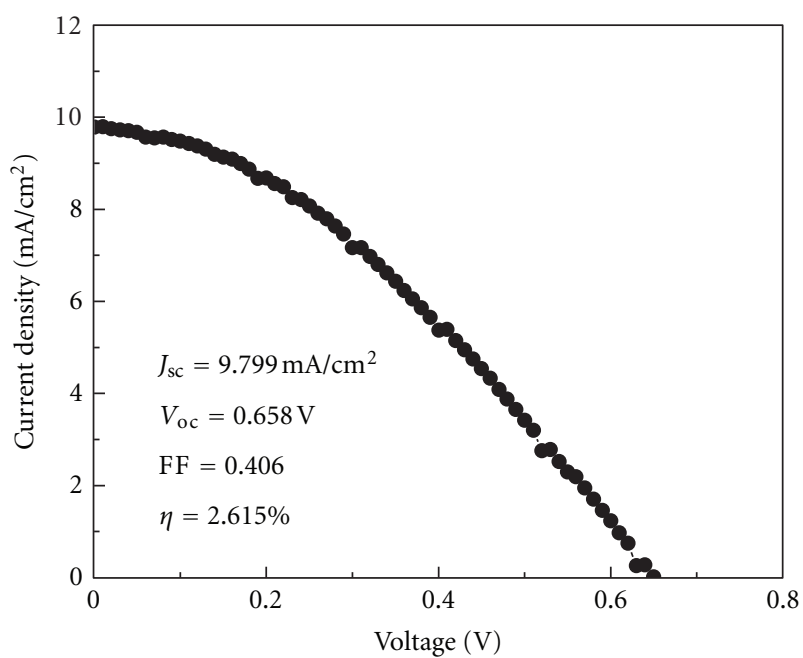

FIgURE 4: $I-V$ curve of DSSC when the electrolyte is just injected.

the Fermi level of $\mathrm{TiO}_{2}$ and the oxidation-reduction potential of electrolyte. To understand the difference in their $J_{\mathrm{sc}}$ for the measurement at initial assembling stage and at one, two, three and so forth hours lately. We conduct the standard $I-V$ curve of the solar cell and discuss the change of the series resistance and the shunt resistance.

It has been known that the tangent slope of vertical part (near $V_{\mathrm{oc}}$ ) is proportional to the reciprocal of the series resistance $\left(1 / R_{s}\right)$ and the tangent slope of transverse part (near $J_{\mathrm{sc}}$ ) is proportional to the reciprocal of the shunt resistance $\left(1 / R_{\mathrm{sh}}\right)$. When $R_{\mathrm{sh}}$ increase or/and $R_{s}$ decrease, F.F. will become better. The tangent slope of $V_{\text {oc }}$ part in Figure 5 is larger than that in Figure 4, which means $R_{s}$ decreases as time goes on. However, the tangent slope of $I_{\mathrm{sc}}$ does not change obviously so that $R_{\mathrm{sh}}$ is almost the same. We thus discuss the factor that affects the series resistance $R_{s}$ and ignores the shunt resistance $R_{\mathrm{sh}}$.

The series-internal resistance of DSSCs was investigated by some researchers based on an equivalent circuit of DSSCs $[4,5]$. It was found that series-internal resistance correlates with the charge-transfer at Pt counter electrode, TCO substrate resistance, and Nernstian diffusion in the

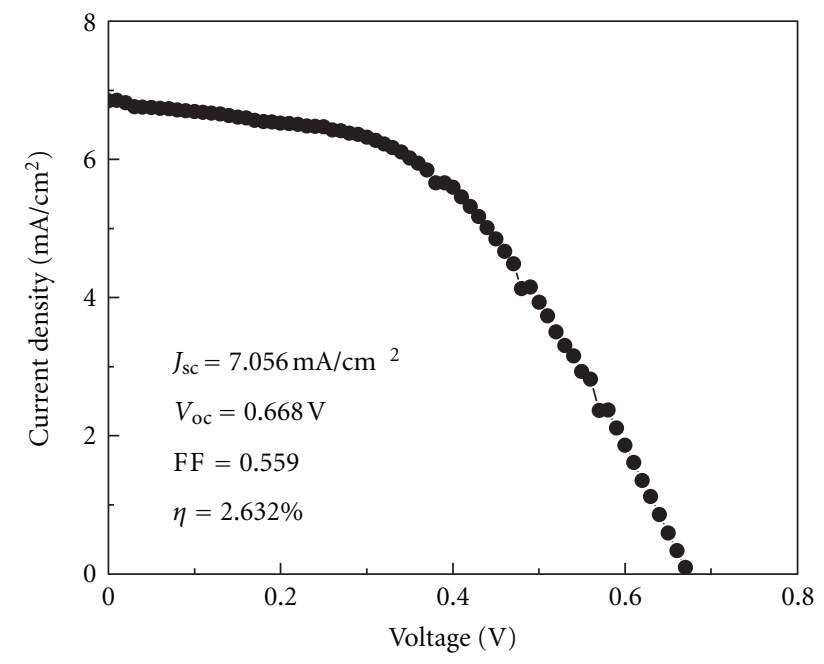

FIGURE 5: $I-V$ curve of DSSC when the electrolyte has been injected and stay for one hour.

electrolyte. According to these, the equivalent circuit of DSSCs is constructed as shown in Figure 6. The series resistance is the sum of the charge transfer resistance at $\mathrm{Pt} /$ electrode interface $\left(R_{1}\right)$, the diffusion resistance of $\mathrm{I}_{3}{ }^{-}$ ions in electrolyte $\left(R_{2}\right)$, and the sheet resistance of TCO $\left(R_{h}\right)$. Because $R_{1}$ and $R_{h}$ relate to the property of the material, they cannot change as time goes on. We think the major factor that influences $R_{s}$ must be $R_{2}$. The probable explanation is that the electrolyte only contacts the top surface of $\mathrm{TiO}_{2}$ thin film when the electrolyte is just injected. However, the electrolyte may permeate into the mesoporous film after an hour and the contact area with dye-adsorbed $\mathrm{TiO}_{2}$ will increase, so the charge-transfer from the electrolyte to the oxidized dye will be accelerated. The large contact area between the electrolyte and the dye-adsorbed $\mathrm{TiO}_{2}$ film improve the rate of $I_{3}{ }^{-}$reduction and hence decrease $R_{s}$.

According to the diode equation that correlates with Figure 6:

$$
I=I_{\mathrm{ph}}-I_{o}\left\{\exp \left[\frac{q\left(V+I R_{s}\right)}{n k T}\right]-1\right\}-\frac{V+I R_{s}}{R_{\mathrm{sh}}},
$$




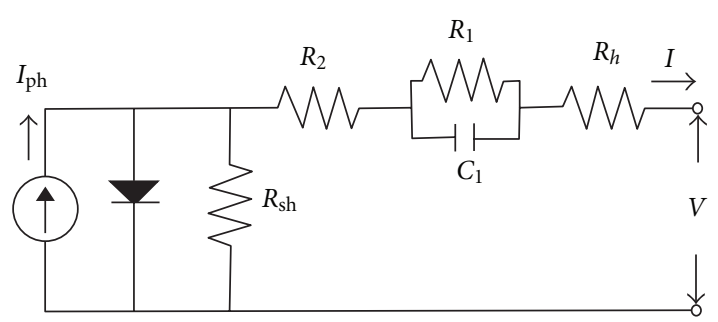

FIGURE 6: Equivalent circuit based on current-voltage characteristics of DSSCs. The sum of $R_{1}, R_{2}$, and $R_{h}$ corresponds closely to the series resistance of DSSCs. $C_{1}$ is capacitance elements.

where $I_{\mathrm{ph}}$ is the ideal photocurrent, $I_{0}$ is the reverse saturation current, $n$ is the ideality factor whose value is between 1 and 2 for the DSSC, $R_{s}$ is the series resistance which is the sum of $R_{1}, R_{2}$, and $R_{h}$, and $R_{\text {sh }}$ is the shunt resistance. The gain in open circuit voltage can be calculated from (3):

$$
V_{\mathrm{oc}}=\frac{n k T}{q} \ln \left[\frac{I}{I_{o}}-\frac{V_{\mathrm{oc}}}{I_{o} R_{\mathrm{sh}}}+1\right] .
$$

As $R_{\text {sh }}$ increase, $V_{\text {oc }}$ will also increase. as comparing Figure 4 to Figure 5 , it is found that $V_{\mathrm{oc}}$ does not change obviously. Since $1 / R_{s}$ is unchanged, it confirms that the shunt resistance in DSSCs is almost the same as time goes on.

The short circuit current can be obtained from (3) when $V=0$, and it can be found that $I_{\mathrm{sc}}$ will increase as $R_{s}$ decreases. However, $J_{\mathrm{sc}}$ decreases from $9.799 \mathrm{~mA} / \mathrm{cm}^{2}$ in Figure 4 to $7.056 \mathrm{~mA} / \mathrm{cm}^{2}$ in Figure 5 . It must be the influences of the dark current which correlates with the recombination of charge carriers by reduction of $\mathrm{I}_{3}{ }^{-}$at dyefree $\mathrm{TiO}_{2}$ surface and bare FTO surface exposed to electrolyte through porous electrode [6]. As we discussed before, the electrolyte will permeate into the mesoporous film when DSSC has been staid for an hour. It may apply the electrolyte to contact the dye-free $\mathrm{TiO}_{2}$ surface and even the FTO surface, so that accelerates the recombination of the charge carriers from the conduct band of $\mathrm{TiO}_{2}$ to the electrolyte and produces the reverse saturation current. The increase of the dark current lowers $I_{\mathrm{sc}}$ seriously so that it is important to modify the working electrode surface to decrease the reverse charge flow.

Based on the above discussion, it is known how to improve the performance of DSSCs by modifying the interface between the working electrode and the electrolyte, as investigated by some research workers [7-9]. Su et al. fabricated layer-by-layer $\mathrm{Au}$ nanoparicles, which were prepared using chemical reduction method, onto the working electrode as a Schottky barrier in a water-based DSSC [10]. It was found that an interfacial blocking layer could suppress the interfacial recombination between $\mathrm{TiO}_{2}$ and excited dye molecules or $\mathrm{I}^{-} / \mathrm{I}_{3}{ }^{-}$couple, which led to an improvement on cell performance [7-9]. Moreover, in order to improve the performance of DSSCs, it is also necessary to suppress the dark current. The reverse charge flow, recapture of the electron by the electrolyte, could be impaired by judicious design of the sensitizer. It can also form a tightly packed insulating monolayer blocking the dark current.
Consequently, decreasing the recombination of charges in the dye or electrolyte is one of the important issues to increase the conversion efficiency of DSSC and is worthy of ongoing study.

\section{Conclusion}

In this study, we discussed the change of the current-voltage characteristics in DSSCs as time goes on and found that fill factor (F.F) got better but short circuit current density $J_{\mathrm{sc}}$ decreased. The results were explained by using the variation of the series resistance in the equivalent circuit of the DSSC. The increase of F.F. may result from the decrease of series resistance $R_{s}$ due to the electrolyte permeating into the mesoporous working electrode and hence increase the contact area with the dye-adsorbed $\mathrm{TiO}_{2}$. However, it also applies the electrolyte to contact the dye-free $\mathrm{TiO}_{2}$ surface and even the FTO surface, so that accelerates the recombination of the charge carriers from the conduct band of $\mathrm{TiO}_{2}$ to the electrolyte and produces the reverse saturation current.

\section{References}

[1] B. O’Regan and M. Grätzel, "A low-cost, high-efficiency solar cell based on dye-sensitized colloidal $\mathrm{TiO}_{2}$ films," Nature, vol. 353, no. 6346, pp. 737-740, 1991.

[2] M. Grätzel, "Photoelectrochemical cells," Nature, vol. 414, no. 6861, pp. 338-344, 2001.

[3] A. Hagfeldt and M. Grätzel, "Molecular photovoltaics," Accounts of Chemical Research, vol. 33, no. 5, pp. 269-277, 2000.

[4] L. Han, N. Koide, Y. Chiba, and T. Mitate, "Modeling of an equivalent circuit for dye-sensitized solar cells," Applied Physics Letters, vol. 84, no. 13, pp. 2433-2435, 2004.

[5] L. Han, N. Koide, Y. Chiba et al., "Improvement of efficiency of dye-sensitized solar cells by reduction of internal resistance," Applied Physics Letters, vol. 86, no. 21, Article ID 213501, 3 pages, 2005.

[6] W. J. Lee, E. Ramasamy, D. Y. Lee, and J. S. Song, "Glass frit overcoated silver grid lines for nano-crystalline dye sensitized solar cells," Journal of Photochemistry and Photobiology A, vol. 183, no. 1-2, pp. 133-137, 2006.

[7] A. Kay and M. Grätzel, "Dye-sensitized core-shell nanocrystals: improved efficiency of mesoporous tin oxide electrodes coated with a thin layer of an insulating oxide," Chemistry of Materials, vol. 14, no. 7, pp. 2930-2935, 2002.

[8] E. Palomares, J. N. Clifford, S. A. Haque, T. Lutz, and J. R. Durrant, "Slow charge recombination in dye-sensitised solar cells (DSSC) using $\mathrm{Al}_{2} \mathrm{O}_{3}$ coated nanoporous $\mathrm{TiO}_{2}$ films," Chemical Communications, no. 14, pp. 1464-1465, 2002.

[9] E. Palomares, J. N. Clifford, S. A. Haque, T. Lutz, and J. R. Durrant, "Control of charge recombination dynamics in dye sensitized solar cells by the use of conformally deposited metal oxide blocking layers," Journal of the American Chemical Society, vol. 125, no. 2, pp. 475-482, 2003.

[10] Y. H. Su, W. H. Lai, L. G. Teoh, M. H. Hon, and J. L. Huang, "Layer-by-layer Au nanoparticles as a Schottky barrier in a water-based dye-sensitized solar cell," Applied Physics A, vol. 88, no. 1, pp. 173-178, 2007. 

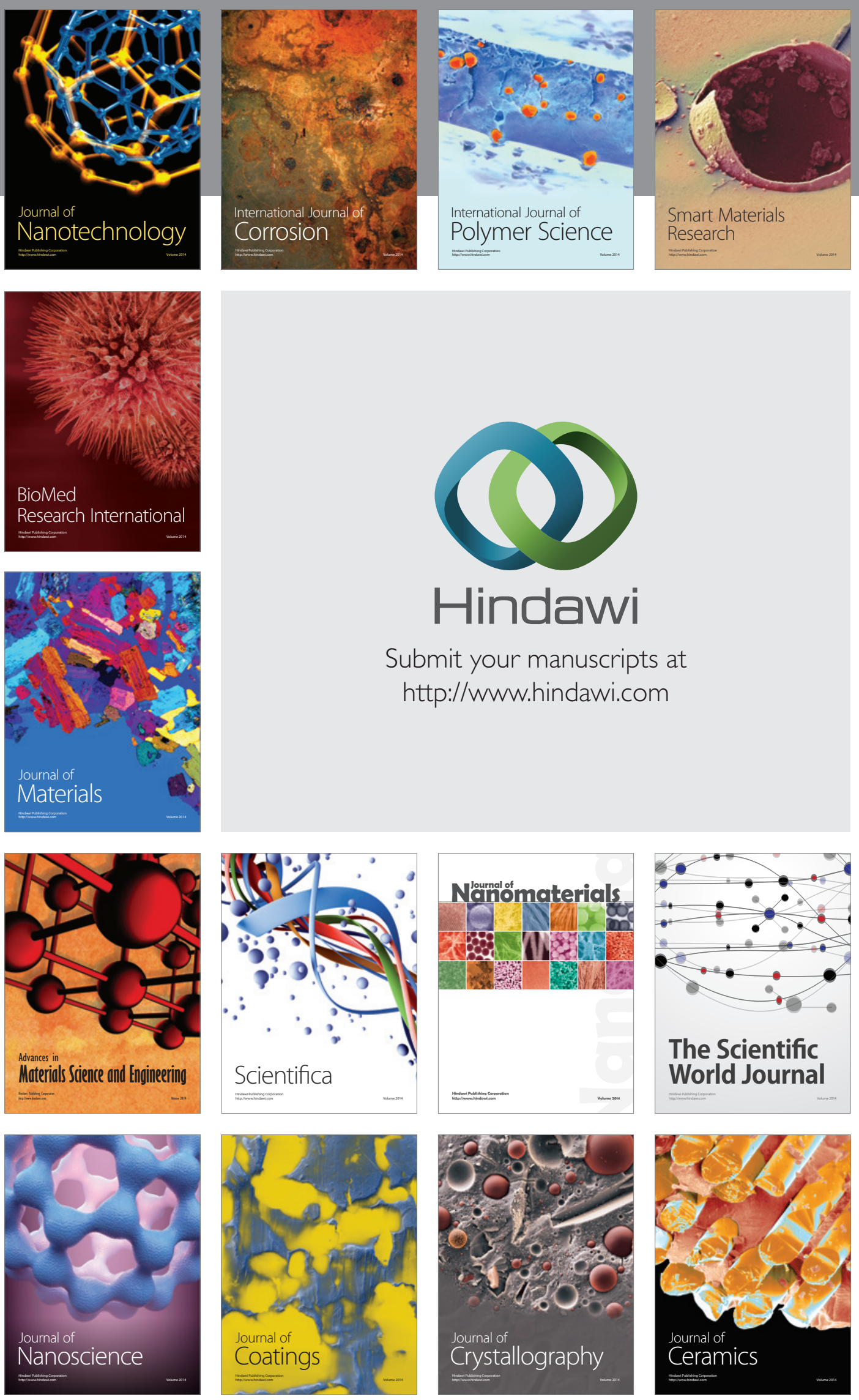

The Scientific World Journal

Submit your manuscripts at

http://www.hindawi.com

\section{World Journal}

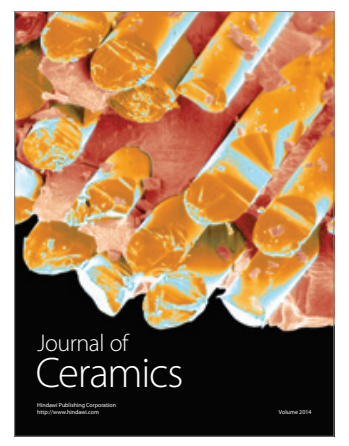

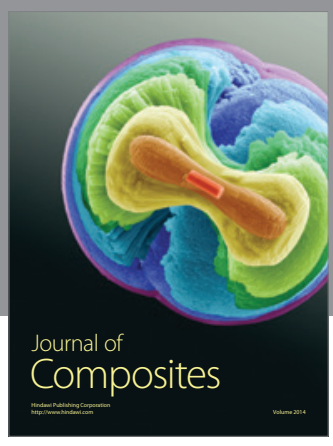
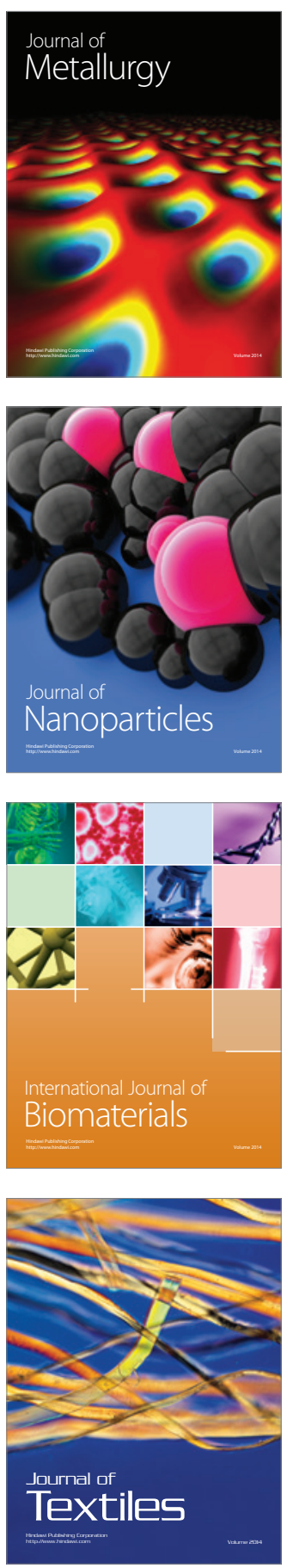